GRASAS Y ACEITES 65 (4)

October-December 2014, e042

ISSN-L: 0017-3495

doi: http://dx.doi.org/10.3989/gya.0350141

\title{
Effect of carvacrol on the oxidative stability of palm oil during frying
}

\author{
T. İnanç and M. Maskan ${ }^{\bowtie}$ \\ Gaziantep University, Engineering Faculty, Food Engineering Department, 27310 Gaziantep-Turkey \\ ${ }^{\square}$ Corresponding author: maskan@gantep.edu.tr
}

Submitted: 24 March 2014; Accepted: 2 June 2014

SUMMARY: Fats and oils deteriorate physically and chemically at frying temperatures due to several reasons. The objective of this study was to assess the effect of carvacrol on the oxidative stability of palm oil during a repeated frying process. Potatoes were serially fried in carvacrol-added palm oil, BHT-added palm oil and a control oil (without any antioxidants). After each tenth frying cycle, several chemical analyses were carried out on collected samples to evaluate deterioration in the oils. The free fatty acid, para-anisidine, iodine, and total polar component values of the fresh oil were $0.080,2.85,57.1$ and 7.5 , respectively. These values changed to $0.165,11.80,46.7,11.0$, respectively for the control oil; $0.151,11.28,49.2$ and 10.5 for BHT-added oil; 0.140 , $7.19,51.7,10.0$ for carvacrol-added oil after 40 frying cycles. The results revealed that the use of carvacrol could significantly improve the oxidative stability of palm oil when compared to the control samples. This effect was also comparable to BHT. Using carvacrol in frying oil slowed down the rate of the formation of conjugated dienes and trienes compared to the oil with BHT and the control. The frying process significantly changed the viscosity of the oil samples.

KEYWORDS: Carvacrol; Frying; Natural antioxidant; Oxidative stability; Palm oil

RESUMEN: Efecto del carvacrol en la estabilidad oxidativa del aceite de palma durante la fritura. Las grasas y aceites se deterioran física y químicamente a las temperaturas de fritura debido a diferentes razones. El objetivo de este estudio fue evaluar el efecto del carvacrol en la estabilidad oxidativa del aceite de palma durante el proceso de fritura repetida. Se sometió a fritura repetida patatas en el aceite de palma con carvacrol agregado, en aceite de palma con BHT agregado y en aceite control (sin antioxidante). Después de cada décimo ciclo de fritura, se realizaron diferentes análisis sobre las muestras recogidas para evaluar el deterioro de los aceites. Ácidos grasos libre, para-anisidina, índice de yodo y componentes polares totales del aceite fresco fueron: 0,080, $2,85,57,1$ y 7,5 , respectivamente. Estos valores cambian a $0.165,11.80,46.7$ y 11.0 , respectivamente, para el aceite de control; 0.151, 11.28, 49.2 y 10.5 para el aceite con BHT añadido; 0.140, 7.19, 51.7 y 10.0 para el aceite con carvacrol añadido después de 40 frituras. Los resultados revelaron que el uso de carvacrol puede mejorar significativamente la estabilidad oxidativa del aceite de palma en comparación con las muestras control. Este efecto también era comparable a la del BHT. El uso de carvacrol en el aceite de fritura ralentizó la velocidad de formación de dienos y trienos conjugados en comparación con el aceite con BHT y el de control. Los procesos de fritura producen grandes cambios en la viscosidad de las muestras de aceite.

PALABRAS CLAVE: Aceite de palma; Antioxidante natural; Carvacrol; Estabilidad a la oxidación; Fritura

Citation/Cómo citar este artículo: İnanç T, Maskan M. 2014. Effect of carvacrol on the oxidative stability of palm oil during frying. Grasas Aceites 65 (4): e042. doi: http://dx.doi.org/10.3989/gya.0350141.

Copyright: (C) 2014 CSIC. This is an open-access article distributed under the terms of the Creative Commons Attribution-Non Commercial (by-nc) Spain 3.0 Licence. 


\section{INTRODUCTION}

The great demand of food prepared in a cheap and quick way due to the rapid increase in population, excess urbanization and economical drawbacks has resulted in an increase in the production and consumption of the ready-foods, especially fried foods all around the world. Therefore, most of the fats and oils are used in the frying of food materials.

Frying is a fast, convenient and energy efficient method and therefore it is widely used in fast-food restaurants and domestic cooking. Despite the trend towards low-fat foods, fried foods have become more and more popular with their unique sensorial properties, since frying increases the palatability of foods due to fat absorption, crust formation and desired flavors and odors (Farhoosh and Moosavi, 2008).

Besides desirable changes, frying causes undesirable changes which finally result in the deterioration of oil leading to a shortening of the oil's frying life. These negative changes in the oil affect the quality of fried food at the same time. The most important reaction causing oil deterioration which affects both the sensory and nutritional quality of the food product is lipid oxidation. During the frying period, the oxidation process occurs rapidly during the heating of oil in the presence of air. The compounds formed as a result of oxidation cause off-tastes and offflavors in the fried products, reducing the organoleptic characteristics and perhaps causing a health hazard (Moreira et al., 1999, Innawong, 2001).

Options for enhancing the stability of oils during frying process include the use of natural antioxidants rather than synthetic ones due to their adverse effects. Previous studies have generally focused on plant extracts including different plant organs such as seeds, fruits, leaves and others. These studies revealed that using plant extracts is more effective than directly adding the plants for stabilizing the oils. In addition to plant extracts, essential oils and active components have been used as natural antioxidants for stabilizing the polyunsaturated oils. However, essential oils generally have weak antioxidative effects at higher temperatures, whereas they are very effective at storage temperatures. This may also be due to decomposition and/or volatility of the essential oils taking place at very high temperatures (Tomaino et al., 2005, Maestri et al., 2006, Al-Jaber et al., 2011, Inanc and Maskan, 2013).

Plants also have active components namely phenolics and polyphenolics that are known to act as antioxidants. Carvacrol, which is one of the strong active components, is predominantly present in oregano, but also naturally available in thyme, clove and cinnamon (Yanishlieva et al., 2006). In only a few studies, the active components of plant extracts have been used to slow down the oxidation of oils at high temperatures instead of extracts and essential oils (Zunin et al., 2010, Yeo et al., 2011,
Inanc, 2012). However, it is possible to utilize their advantageous properties in applications at high temperatures in the future.

The undesirable changes in oils during frying partially depend on the unsaturation degree of fatty acids, besides time and temperature of the frying process. Therefore, it is very important to choose the right frying oil to retard oil deterioration. High oxidative stability, high smoke point, low foaming, low melting point and bland flavor are important characteristics of good frying oils (Kochhar, 2000). Palm oil, which is the second largest source of oil in the world, next to soybean oil, is currently the oil most used for frying (FEDIOL, 2012). It has a good oxidative stability due to its high degree of saturation. This is the reason for the selection of palm oil as the frying medium in the current study.

In the present study, potato slices were serially deep-fried in palm oil enriched with a GRAS (Generally Recognized as Safe) active compound carvacrol at $150^{\circ} \mathrm{C}$. This temperature is in the range of adequate frying temperatures in the literature. The carvacrol concentration in the palm oil and the frying temperature were decided as a result of our previous study (Inanc, 2012). Carvacrol was added into palm oil at a concentration of $200 \mathrm{ppm}$, which is the legal usage limit of synthetic antioxidants in most countries according to the Food and Drug Administration (Shahidi, 2005). Thus, it could be comparable with a synthetic antioxidant, butylated hydroxytoluene (BHT). The intended results of the present study should facilitate the frying stability of oils by using natural antioxidants, especially active components instead of synthetic ones.

\section{MATERIALS AND METHODS}

\subsection{Materials}

Fresh potatoes were purchased from a local market. Palm oil was supplied from a manufacturer. Carvacrol and BHT were obtained from Sigma Aldrich Co. (St. Louis, MO).

\subsection{Frying Experiments}

Potato slices were fried in palm oil at $150{ }^{\circ} \mathrm{C}$ and $200 \mathrm{ppm}$ antioxidant concentration. Three sets of frying experiments were performed; natural antioxidant (carvacrol) added oil, BHT added oil and the control oil (without any antioxidants).

The frying process was conducted in an electric deep fat fryer with a thermostate to regulate temperature (Arnica, Deep Fryer, ZG 27A, China). Before starting the frying process, $50 \mathrm{~mL}$ of the oil sample were collected into amber colored glass bottles in order to measure the initial properties of the oil. This oil represents the control oil. Frying was started $30 \mathrm{~min}$ after the temperature 
of the oil had reached the frying temperature. For each frying cycle, $100 \mathrm{~g}$ of sliced fresh potatoes $\left(6.0 \pm 1.23 * 7.8 \pm 1.25 * 49.5 \pm 4.09 \mathrm{~mm}^{3}\right)$ were used. The slices were soaked in a $2.5 \% \mathrm{NaCl}$ solution for 5 min prior to frying. This reduces the oil absorption capacity and prevents surface darkening of the potato slices due to oxidation. Following the draining of the water, the potato slices were dried by blotting with a paper towel before frying. The potatoes were fried in 2 liters of oil for 4 minutes. This period was decided from preliminary experimental studies to reach the $2 \%$ moisture content of potatoes. Then, the oil was heated for $5 \mathrm{~min}$ in order to attain the frying temperature again. For each set, a total of 40 frying cycles were done with the same oil. Fresh oil was not added between the cycles. After each tenth frying cycle, the oil was allowed to equilibrate for $30 \mathrm{~min}$ at the frying temperature and $50 \mathrm{~mL}$ of the oil sample were collected and stored at $4{ }^{\circ} \mathrm{C}$ for further analysis.

\subsection{Measurement of Oil Deterioration During the Frying Process}

After each tenth frying cycle, several analyses were conducted such as free fatty acid content (AOCS, 1989), para-anisidine value (IUPAC, 1987), iodine value (AOAC, 1990), polar compounds (Hampikyan et al., 2011), conjugated dienes and trienes (PORIM, 1995). The rheological behavior of the used oil sample at the $40^{\text {th }}$ frying was determined in the shear rate range of $1-200 / \mathrm{s}$ at $25^{\circ} \mathrm{C}$ by using Haake Rheostress RS1 controlled stress rheometer as described by Maskan (2003). All analyses were made in triplicate. The data were analyzed for significant differences by one-way analysis of variance and compared by Duncan's multiple range test at 5\% significance level using SPSS 16.0 software.

\section{RESULTS AND DISCUSSIONS}

\subsection{Change in Free Fatty Acids (FFA)}

During frying, oil is exposed to air and moisture at elevated temperatures resulting in the hydrolysis of triacylglycerols. This leads to a release of free fatty acids. The released fatty acids are more susceptible to thermal oxidation and cause off-flavors and odors in the frying medium and fried foods (Bensmira et al., 2007). In the current study, FFA values increased with the number of fryings in palm oil as shown in Figure 1. However, carvacrol slowed down the formation of FFA significantly $(p<0.05)$. According to the statistical analysis, the effect of the number of fryings on the increase in FFA in all oil samples was significant $(\mathrm{p}<0.05)$ (i.e., at 10, 20, 30 or 40 frying cycles, the FFA contents in the BHT and carvacrol added and control oils increase). This is in good agreement with several previous works

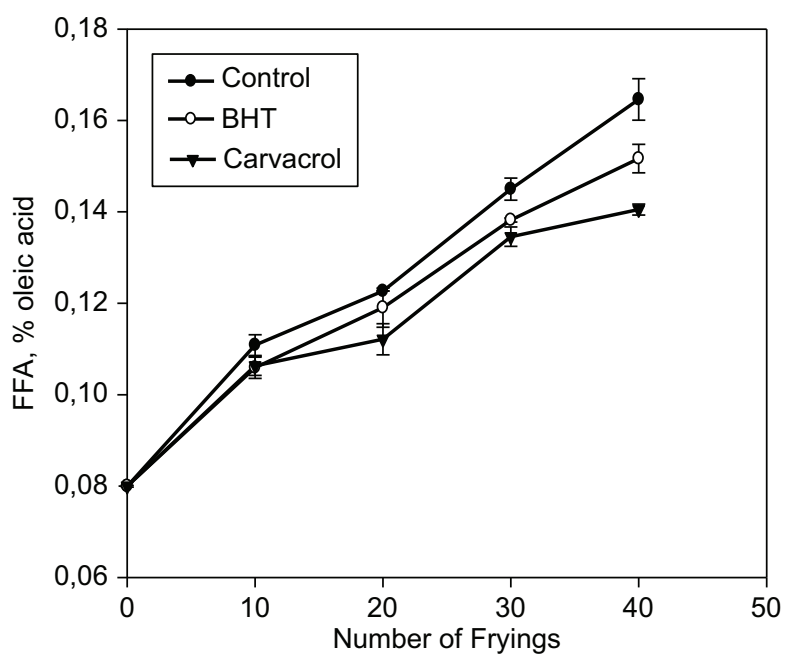

FIGURE 1. Changes in FFA against the number of frying sessions for palm oil samples $(n=3)$.

(Marco et al., 2007, Iqbal et al., 2008, Nor et al., 2009, Kalogianni et al., 2011).

Treatment of oils with antioxidants significantly decreased the FFA of palm oil at each frying cycle as the results compared to the control oil $(\mathrm{p}<0.05)$. Carvacrol was found to be more effective than BHT. Multiple comparison tests showed that the positive effect of carvacrol was significantly different from BHT and control oils. Several researchers found similar results in their studies about the effectiveness of natural antioxidant in vegetable oils (Che Man and Jaswir, 2000, Bensmira et al., 2007, Iqbal et al., 2008, Nor et al., 2009).

\subsection{Changes in para-Anisidine Value ( $p$-AV)}

The para-anisidine value is a measure of the contents of aldehydes which are secondary oxidation products formed when hydroperoxides decompose (Shahidi, 2005). Thus, it is reasonable to measure $p$-AV rather than peroxide value in order to determine the degree of deterioration in oil during frying. The changes in the $p$-AV of the palm oil samples during a series of frying are presented in Figure 2. The $p$-AV of all the oil samples increased as the frying number increased. These findings are in good agreement with several studies (Isabei and Mariano, 2001, Naz et al., 2008). A statistical analysis of the results showed the significant effect $(p<0.05)$ of frying numbers on the increase in $\mathrm{p}-\mathrm{AV}$ of the oils. From Figure 2, it could be determined that the $p$-AV of the oil samples treated with carvacrol were distinctly lower than that of the $\mathrm{BHT}$ and control samples. However, the final $p$-AV of BHT and carvacrol added oils were not very different from each other. The para-anisidine values finally increased from 2.85 to $7.19,11.28$, and 11.80 for samples with carvacrol, BHT, and the control, respectively. 


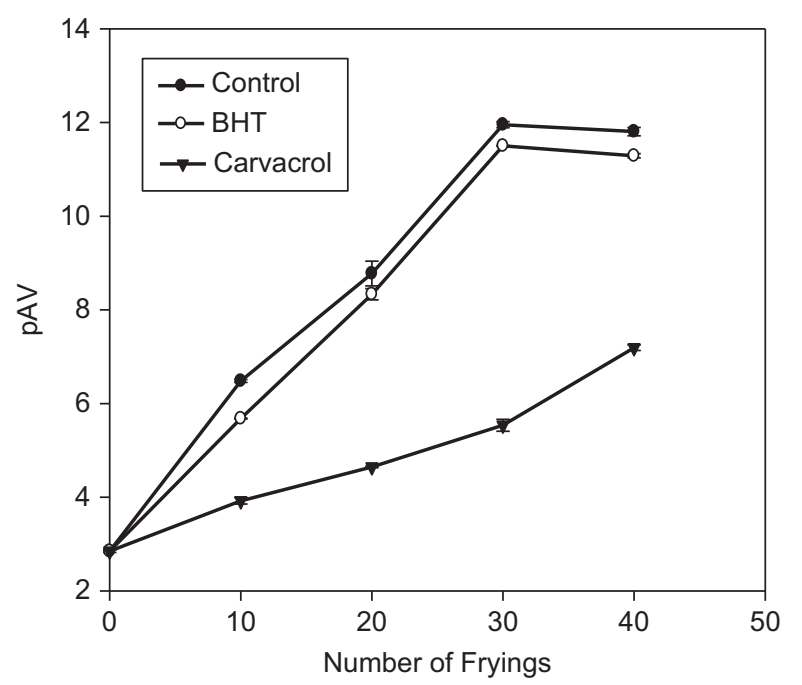

Figure 2. Changes in $p-\mathrm{AV}$ against the number of frying sessions for palm oil samples.

The ANOVA and multiple comparison test results showed that there were significant $(p<0.05)$ differences among the antioxidant-treated oils and the control. From the graph it could be easily understood that carvacrol had a greater effect on the reduction in $p$-AV of the palm oil than the synthetic antioxidant, BHT (Figure 2). The results of several authors studying palm oil are in good agreement with our findings (Ismail, 2005, Nor et al., 2009, Pambou-Tobi et al., 2010).

\subsection{Change in Iodine Value (IV)}

Iodine value is a measure of the total number of unsaturated double bonds present in oil. The differences in iodine values of oils during frying are also good indicators of deterioration in the oils (Che Man and Jaswir, 2000). Oxidation, which consists of a complex series of chemical reactions, is characterized by a decrease in the total unsaturated content of the oil due to the abstraction of hydrogen adjacent to a double bond and the formation of free radicals (Naz et al., 2004).

The change in the IV of the palm oil samples are presented in Figure 3. There was a decrease in IV from 57 to $51.7,49.2$, and 46.7 for samples with carvacrol, BHT, and the control, respectively. The decrease in IV can be attributed to the destruction of double bonds by oxidation and polymerization (Abdulkarim et al., 2008).

The effect of frying numbers on the decrease in IV of all oil samples was generally found to be significant $(\mathrm{p}<0.05)$ according to the ANOVA results. This is in good agreement with the previous studies (Che Man and Jaswir, 2000, Naz et al., 2004, Nor et al., 2009). However, the difference between the

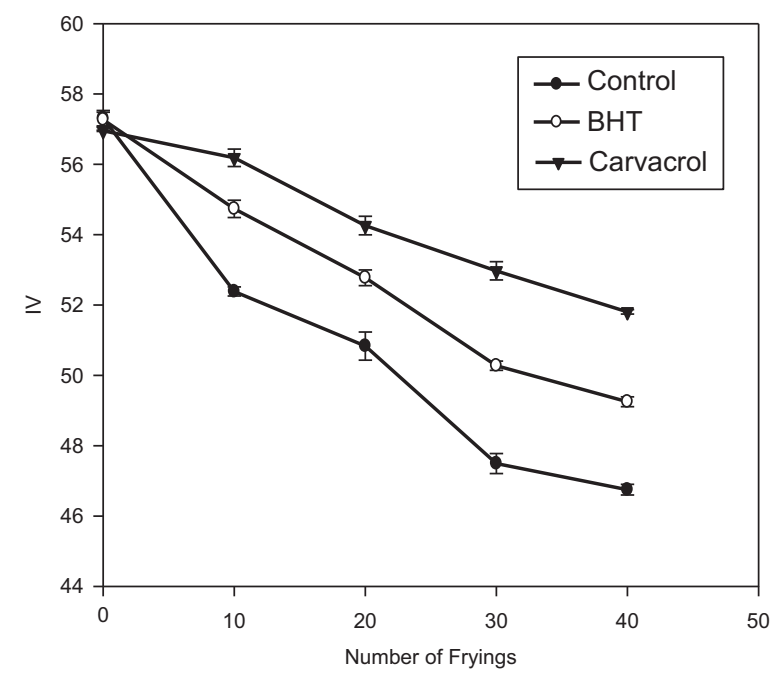

FIGURE 3. Changes in IV against the number of frying sessions for palm oil samples.

values of the 30th and 40th frying in all samples were not significant $(\mathrm{p}>0.05)$.

The use of antioxidants caused a significant reduction in the IV of palm oils compared with the control values $(\mathrm{p}<0.05)$. It could be determined from Figure 3 and the multiple comparison tests that carvacrol was found to be more effective on the IV of the oils than BHT $(\mathrm{p}<0.05)$. Nor et al. (2008) reported similar results with a natural antioxidant used in their study. However, in another study, it was reported that there was no significant difference between thymbra spicata essential oil, whose active component is carvacrol, and BHT with respect to iodine value changes in the oils (Nacaroglu, 2006).

\subsection{Changes in Total Polar Compounds (TPC)}

The amounts of total polar compounds that are formed through oxidation, thermal and hydrolytic reactions during frying, indicate the degree of deterioration in frying oils (Hampikyan et al., 2011, Osawa et al., 2012).

In this study, TPC was measured by an instrument, Testo 265 , which provides accurate results in a very short time compared to the traditional method. The principle of the instrument is based on the measurement of changes in the dielectric constant of frying oil and direct transformation of them into the percentage in the weight of polar compounds (Hampikyan et al., 2011, Osawa et al., 2012). When frying oil decomposes thermally or through oxidation processes, its dielectric constant increases (Hein et al., 1998).

Figure 4 shows that in all oil samples the amount of TPC increased with increasing frying periods. 


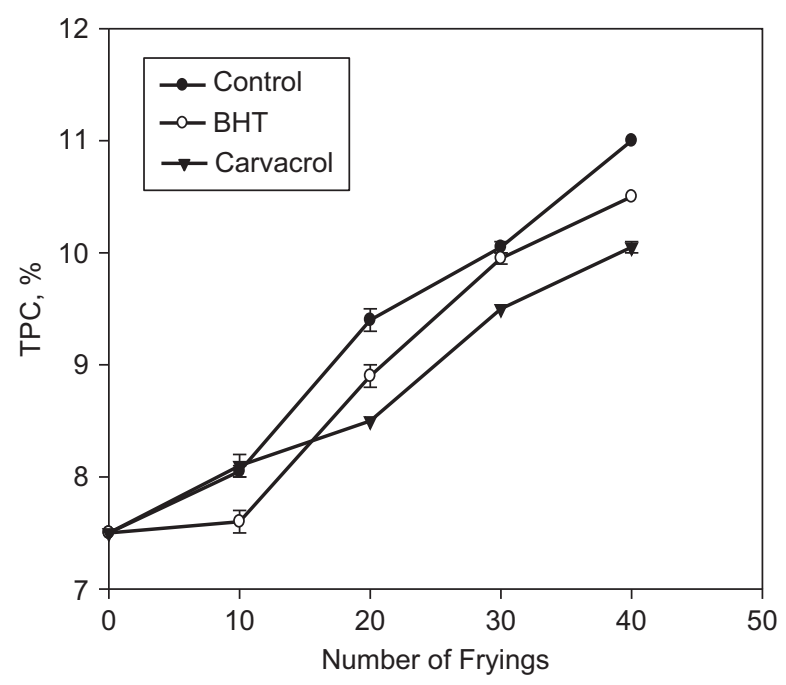

FigurE 4. Changes in TPC against the number of frying sessions for palm oil samples.

The results of Pambou-Tobi et al. (2010) and Romano et al. (2012) agree well with our findings. However, it was determined that there was no significant change in the TPC of the oils with respect to successive frying numbers $(\mathrm{p}>0.05)$. At the end of the frying experiments, the level of polar compounds did not exceed $25 \%$, which is the regulatory limit for frying oils in most European countries (Hampikyan et al., 2011).

Carvacrol was found to be significantly $(\mathrm{p}<0.05)$ effective on slowing down the formation of TPC in palm oil compared to the control samples. However, this effect was not statistically different from the BHT according to the multiple comparison test results ( $p>0.05)$. Nor et al. (2008) also reported the positive effect of a natural antioxidant on the prevention of polar compound formation.

\subsection{Changes in Conjugated Dienes and Trienes in Oils}

Lipids exhibit a shift in their double-bond position because of isomerization and conjugate formation during oxidation. The conjugated dienes (CD) formed show ultraviolet absorption at about $232 \mathrm{~nm}$. Likewise, conjugated trienes (CT) exhibit absorption at about $270 \mathrm{~nm}$. The increases in CD and CT might be proportional to the uptake of oxygen which is analogous to the oxidation of oils (Akoh and Min, 2002). Thus, the determination of $C D$ and $C T$ is known to be a reliable method for measuring the oxidative deterioration of oils. Several authors used CD and CT measurements to evaluate the effect of some antioxidants on vegetable oils. For instance, Houhoula et al. (2004), Arabshahi-Delouee et al. (2011), and Ramadan and Wahdan (2012) used

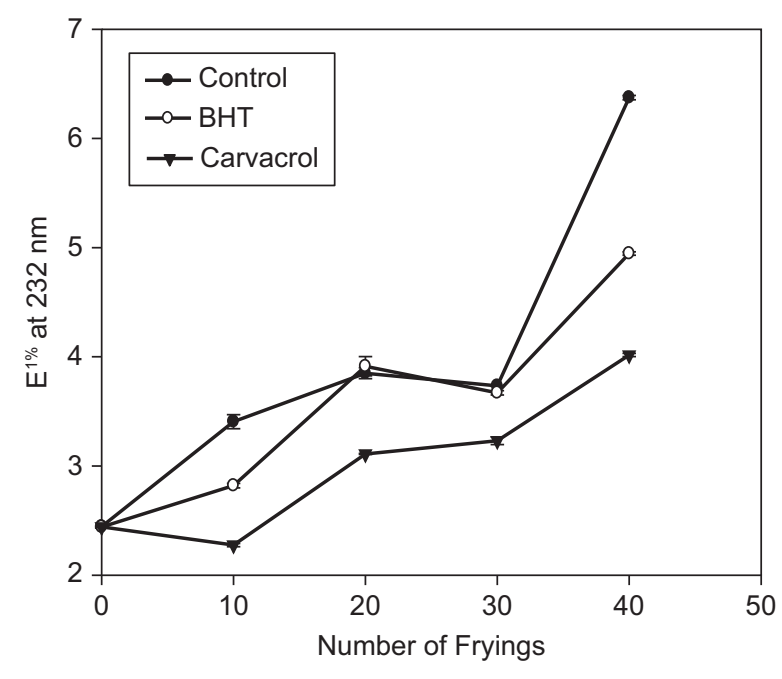

Figure 5. Changes in E1\% at $232 \mathrm{~nm}$ against the number of frying sessions for palm oil samples.

absorption in the UV spectrum to evaluate the oxidative deterioration of oils in their studies.

The results in the current study revealed that there were increasing trends in both specific extinction, the $\mathrm{E}^{1 \%}$ values of 232 and $270 \mathrm{~nm}$ corresponding to the $\mathrm{CD}$ and $\mathrm{CT}$ contents for all of the oil samples with increasing frying numbers (Figures 5 and 6). However, the statistical analysis showed that the effect of frying numbers was not significant $(p>0.05)$ on the increase in CD and CT formation in all oil samples. Using carvacrol in frying oil slowed down the rate of the formation of CD and CT compared to the samples with BHT and the control.

It was easily understood that the amounts of CT were much lower than those of CD in all the oil samples. The reason, as reported by Abdulkarim et al. (2008), may be due to higher linoleic acid contents of the samples than linolenic acid. Conjugated dienes formation is mainly caused by the presence of polyunsaturated fatty acid whereas trienes are mainly formed by the dehydration of conjugated diene hydroperoxides (Mohdaly et al., 2010).

According to the statistical analysis, there were significant $(\mathrm{p}<0.05)$ differences among the extinction coefficients of the oils treated with antioxidants and the control samples. Serjouie et al. (2010) reported similar results to ours. Similarly, the study of Mohdaly et al. (2011) on treatment of natural antioxidant was found to be in good agreement with our results.

There was a decreasing trend in the specific extinction values of the oils between the $20^{\text {th }}$ and $30^{\text {th }}$ frying cycle and then an additional increase from the $30^{\text {th }}$ to the $40^{\text {th }}$ frying cycle. This might be explained by the probable equilibrium between the formation rate of conjugated dienes and the rate at which those 


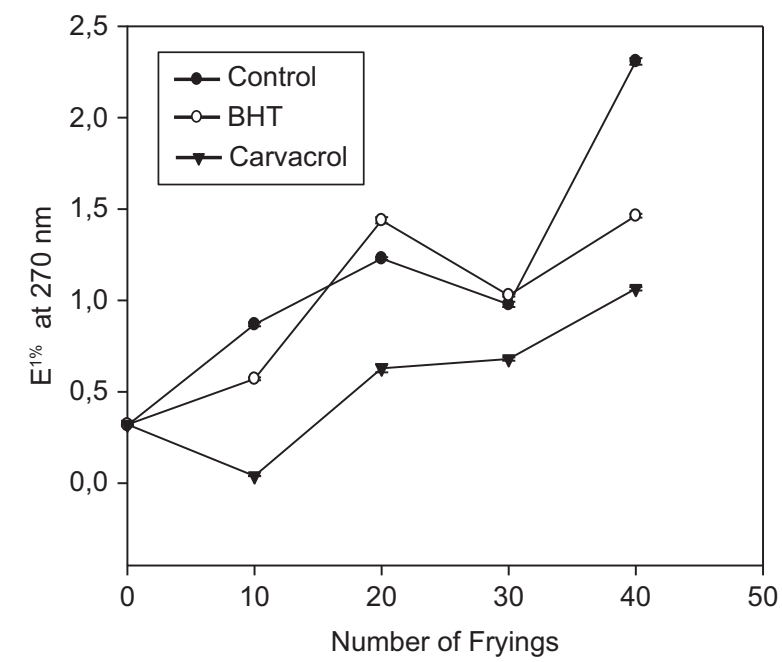

Figure 6. Changes in E1\% at $270 \mathrm{~nm}$ against the number of frying sessions for palm oil samples.

compounds formed polymers. This might be due to both the formation and decomposition of peroxides at the same time during frying (Pambou-Tobi et al., 2010; Serjouie et al., 2010).

\subsection{Changes in Rheological Behavior of Oils}

Rheological changes in the oils can be also considered an indicator of oil deterioration. During frying at elevated temperatures, the carbon in the fatty acid molecules causes cross linking of the carbon to form cyclic compounds, dimers, trimers, epoxides and polymers, resulting in increased oil viscosity (Kusucharid et al., 2009). It was reported in several studies that the viscosity of frying oils increased mainly as a result of oxidation and polymerization reactions (Bensmira et al., 2007, Kalogianni et al., 2011).

Shear stress measurements as a function of shear rate for palm oil samples collected after the $40^{\text {th }}$ frying are shown in Figure 7. The graph demonstrated that palm oil exhibits non-Newtonian behavior because of the non-linear relationship between shear stress and shear rate. Figure 8 shows the change in apparent viscosity against the shear rate for palm oil samples. Increasing shear rate resulted in decrease in the apparent viscosity of palm oil. This behavior represents shear thinning behavior.

Both of the figures show that neither frying numbers nor antioxidant treatment importantly changed viscosity of the oil samples. However, according to the statistical analysis there was a significant difference $(p<0.05)$ among the viscosities of palm oil samples. Multiple comparison tests also show that fried palm oils were significantly different $(p<0.05)$ from the fresh control sample.

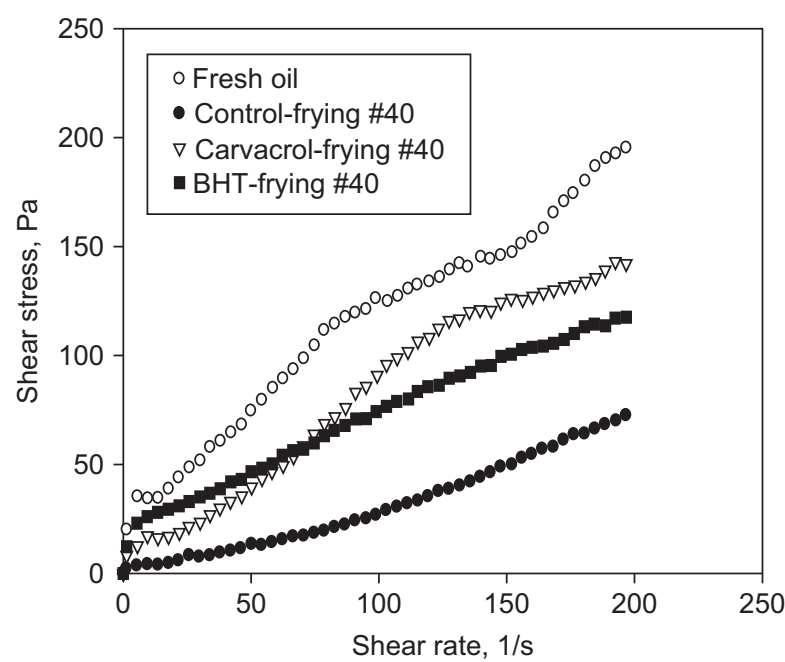

FIGURE 7. Changes in shear stress as a function of shear rate for palm oil samples.

On the other hand, in several studies it was reported that long periods of frying caused a high increase in viscosity due to the highly formation of polar compounds (Che Man and Jaswir, 2000, Kusucharid et al., 2009, Serjouie et al., 2010). The differences between the results might be due to fewer frying applications in the present study. The other reason might be the lower temperature that was used in frying than the other studies reported in the literature. The slight increase in polar materials in our study also confirms these findings, since there is a strong correlation between formation of polar compounds and increase in viscosity (Abdulkarim et al., 2008).

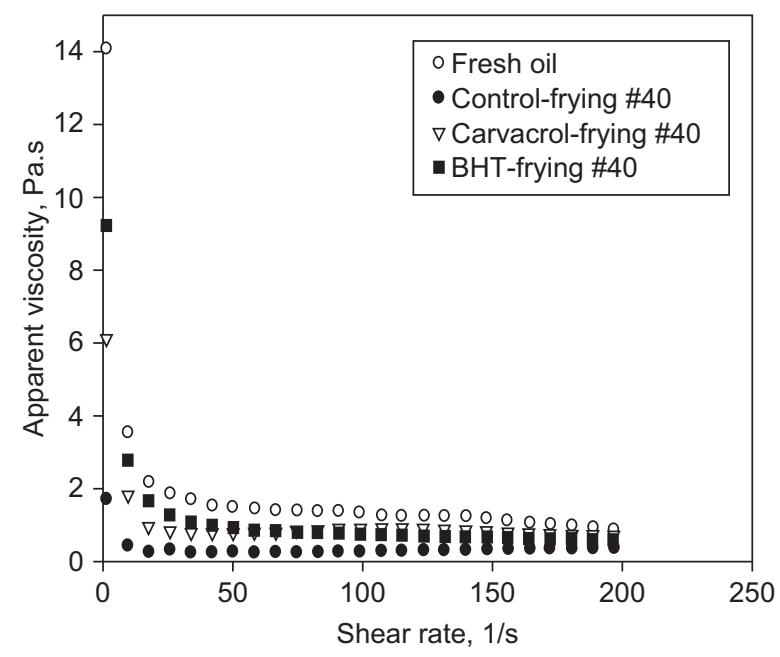

FIGURE 8. Changes in apparent viscosity as a function of shear rate for palm oil samples. 


\section{CONCLUSIONS}

The results of the chemical analysis in oils correlated the good impact of carvacrol on reducing oil oxidation during the frying process. This effect was also comparable to the synthetic antioxidant BHT. Thus, it can be considered as an alternative to the BHT. However, the strong and characteristic flavor of natural antioxidants may adversely affect the sensorial properties of both the oil and the fried food. Therefore, this important aspect should be evaluated in further studies. Exploring natural antioxidants by means of toxicology is also recommended in order to conveniently use them in foods.

\section{ACKNOWLEDGMENTS}

This research project was supported by the University of Gaziantep, Scientific Research Projects Governing Unit (Turkey) (Project No: MF.10.11) which led to this paper.

\section{REFERENCES}

Abdulkarim SM, Frage A, Tan CP, Ghazali HM. 2008. Determination of the extent of frying fat deterioration using differential scanning calorimetry. J. Food Agric. Environ. 6, 54-59.

Akoh CC, Min DB. 2002. Food lipids: Chemistry, nutrition, and biotechnology (2nd Ed.). Marcel Dekker Inc, New York. http://dx.doi.org/10.1201/9780203908815

Al-Jaber NA, Awaad AS, Moses JE. 2011. Review on some antioxidant plants growing in Arab world. J. Saudi Chem. Soc. 15, 293-307. http://dx.doi.org/10.1016/j.jscs.2011.07.004.

AOAC. 1990. Association of Official Analytical Chemistry. Official methods of analysis (15th Ed.). Virginia, USA.

AOCS. 1989. Official Methods and Recommended Practices of the American Oil Chemists' Society (4th Ed.). American Oil Chemists' Society, Champaign, Illinois.

Arabshahi-Delouee S, Aalami M, Urooj A. 2011. Drumstick (Moringa oleifera L.) leaves: A potential source of natural lipid antioxidants. J. Food Process Eng. 34, 947-959. http:// dx.doi.org/10.1111/j.1745-4530.2009.00554.x.

Bensmira M, Jiang B, Nsabimana C, Jian T. 2007. Effect of lavender and thyme incorporation in sunflower seed oil on its resistance to frying temperature. Food Res. Int. 40, 341-346. http://dx.doi.org/10.1016/j.foodres.2006.10.004.

Che Man YB, Jaswir I. 2000. Effect of rosemary and sage extracts on frying performance of refined, bleached and deodorized (RBD) palm olein during deep-fat frying. Food Chem. 69, 301-307. http://dx.doi.org/10.1016/ S0308-8146(99)00270-8.

FEDIOL. 2012. Annual Statistics: Vegetable oils production, imports, exports and consumption. (www.fediol.eu).

Farhoosh R, Moosavi SMR. 2008. Carbonyl value in monitoring of the quality of used frying oils. Anal. Chim. Acta 617, 18-21. http://dx.doi.org/10.1016/j.aca.2007.11.049.

Hampikyan H, Colak H, Akhan M, Turgay I. 2011. Determination of total polar compound (TPC) levels in frying oils. J. Food Agric. Environ. 9, 142-144.

Hein M, Henning H, Isengard HD. 1998. Determination of total polar parts with new methods for the quality survey of frying fats and oils. Talanta 47, 447-454. http://dx.doi. org/10.1016/S0039-9140(98)00148-9.

Houhoula DP, Oreopoulou V, Tzia C. 2004. Antioxidant efficiency of oregano in frying and storage of fried products. Eur. J. Lipid Sci. Technol. 106, 746-751. http://dx.doi. org/10.1002/ejlt.200400995.
Inanc T. 2012. Antioxidative Effects of various herbal extracts on corn and palm oils during frying process. M. Sc. Thesis, Graduate School of Natural and Applied Sciences, University of Gaziantep, Turkey.

Inanc T, Maskan M. 2013. Testing the antioxidant effect of essential oils and BHT on corn oil at frying temperatures: A response surface methodology. J. Am. Oil Chem. Soc. 90, 1845-1850. http://dx.doi.org/10.1007/s11746-013-2351-8

Innawong B. 2001. Improving fried product and frying oil quality using nitrogen gas in a pressure frying system. Ph. D. Thesis, Biological Systems Engineering, Virginia Polytechnic Institute and State University, USA.

Iqbal S, Haleem S, Akhtar M, Zia-ul-Haq M, Akbar J. 2008. Efficiency of pomegranate peel extracts in stabilization of sunflower oil under accelerated conditions. Food Res. Int. 41, 194-200. http://dx.doi.org/10.1016/j. foodres.2007.11.005.

Isabei P, Mariano M. 2001. Study of the thermal stability of edible vegetable oils in different environments. Afinidad 58, 190-196.

Ismail R. 2005. Palm oil and palm olein frying applications. Asia Pac. J. Clin. Nutr. 14, 414-419.

IUPAC. 1987. Standard Methods for the Analysis of Oils, Fats and Derivatives (7th Ed.). Blackwell Scientific, London, UK.

Kalogianni EP, Karapantsios TD, Miller R. 2011. Effect of repeated frying on the viscosity, density and dynamic interfacial tension of palm and olive oil. J. Food Eng. 105, 169-179. http://dx.doi.org/10.1016/j.jfoodeng.2011.02.021.

Kochhar SP. 2000. Stabilization of frying oils with natural antioxidative components. Eur. J. Lipid Sci. Technol. 102, 552-559. http://dx.doi.org/10.1002/14389312(200009)102:8/9<552::AID-EJLT552>3.3.CO;2-M.

Kusucharid C, Jangchud A, Thamakorn P. 2009. Changes in characteristics of palm oil during vacuum and atmospheric frying conditions of sweet potato. Kasetsart Journal: Natural Science, 43, 298-304.

Maestri DM, Nepote V, Lamarque AL, Zygadio JA. 2006. Natural products as antioxidants. Res. Sign. 1, 105-135.

Marco ED, Savarese M, Parisini C, Battimo I, Falco S, Sacchi R. 2007. Frying performance of a sunflower/palm oil blend in comparison with pure palm oil. Eur. J. Lipid Sci. Technol. 109, 237-246. http://dx.doi.org/10.1002/ejlt.200600192.

Maskan M. 2003. Change in colour and rheological behaviour of sunflower seed oil during frying and after adsorbent treatment of used oil. Eur. Food Res. Technol. 218, 20-25. http://dx.doi.org/10.1007/s00217-003-0807-z.

Mohdaly A, Sarhan MA, Mahmoud A, Ramadan MF, Smetanska I. 2010. Antioxidant efficacy of potato peels and sugar beet pulp extracts in vegetable oils protection. Food Chem. 123, 1019-1026. http://dx.doi.org/10.1016/j. foodchem.2010.05.054

Mohdaly A, Smetanska I, Ramadan MF, Sarhan M, Mahmoud A. 2011. Antioxidant potential of sesame (Sesamum indicum) cake extract in stabilization of sunflower and soybean oils. Ind. Crop Prod. 34, 952-959. http://dx.doi. org/10.1016/j.indcrop.2011.02.018.

Moreira RG, Castell-Perez ME, Barrufet MA. 1999. Deepfat frying fundamental and applications (1st Ed.). Aspen Publication, Gaitherburg, MA.

Nacaroglu S. 2006. Effect of butylated hydroxytoluene and essential oils of Thymbra spicata on stability of corn and palm oils during deep-fat frying. M. Sc. Thesis, Graduate School of Natural and Applied Sciences, University of Gaziantep, Turkey.

Naz S, Sheikh H, Siddiqi R, Sayeed S. 2004. Oxidative stability of olive, corn and soybean oil under different conditions. Food Chem. 88, 253-259. http://dx.doi.org/10.1016/j. foodchem.2004.01.042

Naz S, Siddiqi R, Sayeed SA. 2008. Effect of flavonoids on the oxidative stability of corn oil during deep frying. Int. J. Food Sci. Technol. 43, 1850-1854. http://dx.doi. org/10.1111/j.1365-2621.2008.01731.x.

Nor FM, Mohamed S, Idris AN, Ismail R. 2008. Antioxidative properties of Pandanus amaryllifolius leaf extracts in accelerated oxidation and deep frying studies. Food Chem. 
110, 319-327. http://dx.doi.org/10.1016/j.foodchem.2008. 02.004 .

Nor FM, Mohamed S, Idris NA, Ismail R. 2009. Antioxidative properties of Curcuma longa leaf extract in accelerated oxidation and deep frying studies. J. Am. Oil Chem. Soc. 86, 141-147. http://dx.doi.org/10.1007/s11746-008-1335-6.

Osawa CC, Gonçalves LAG, Gumerato HF, Mendes FM. 2012. Study of the effectiveness of quick tests based on physical properties for the evaluation of used frying oil. Food Control 26, 525-530. http://dx.doi.org/10.1016/j. foodcont.2012.01.008.

Pambou-Tobi NP, Nzikou JM, Matos L, Ndangui CB Kimbonguila A, Abena AA, Silou Th, Scher J, Desobry S. 2010. Comparative study of stability measurements for two frying oils: Soybean oil and refined palm oil. Adv. J. Food Sci. Technol. 2, 22-27.

PORIM. 1995. Palm oil research institute of Malaysia, PORIM Test Methods. Miistry of Primary Industries, Malaysia.

Ramadan MF, Wahdan KM. 2012. Blending of corn oil with black cumin (Nigella sativa) and coriander (Coriandrum sativum) seed oils: Impact on functionality, stability and radical scavenging activity. Food Chem. 132, 873-879. http://dx.doi.org/10.1016/j.foodchem.2011.11.054

Romano R, Giordano A, Vitiello S, Le Grottaglie L, Musso SS. 2012. Comparison of the frying performance of olive oil and palm superolein. J. Food Sci. 77, 519-531. http:// dx.doi.org/10.1111/j.1750-3841.2012.02663.x

Serjouie A, Tan CP, Mirhosseini H, Che Man YB. 2010. Effect of vegetable-based oil blends on physicochemical properties of oils during deep-fat frying. Am. J. Food Technol. 5, 310-323. http://dx.doi.org/10.3923/ajft.2010.310.323.

Shahidi F. 2005. Bailey's industrial oil and fat products (6th Ed.). New York, John Wiley \& Sons. http://dx.doi. org/10.1002/047167849X

Tomaino A, Cimino F, Zimbalatti V, Venuti V, Sulfaro V, De Pasquale A, Saija A. 2005. Influence of heating on antioxidant activity and the chemical composition of some spice essential oils. Food Chem. 89, 549-554. http://dx.doi. org/10.1016/j.foodchem.2004.03.011.

Yanishlieva NV, Marinova E, Pokorny J. 2006. Natural antioxidants from herbs and spices. Eur. J. Lipid Sci. Technol. 108, 776-793. http://dx.doi.org/10.1002/ejlt.200600127.

Yeo J, Park J, Lee J. 2011. Evaluation of antioxidant capacity of sesamol and free radical scavengers at different heating temperatures. Eur. J. Lipid Sci. Technol. 113, 910-915. http://dx.doi.org/10.1002/ejlt.201000553.

Zunin P, Leardi R, Bisio A, Boggia R, Romussi G. 2010. Oxidative stability of virgin olive oil enriched with carnosic acid. Food Res. Int. 43, 1511-1516. http://dx.doi. org/10.1016/j.foodres.2010.04.002. 